\title{
The role of regional flaps in locally advanced cancer larynx with skin invasion Mohamed Zahran, Ahmed Youssef
}

Department of Otolaryngology, School of Medicine, Alexandria University, Alexandria, Egypt

Correspondence to Mohamed Zahran, MD, PhD, Department of Otolaryngology, Faculty of Medicine, Champollion Street, El-Azareeta, Alexandria, Egypt. Tel: +20 1228200928 e-mail: abdelnaby00@hotmail.com

Received 1 July 2018

Accepted 1 August 2018

The Egyptian Journal of Otolaryngology 2018, 34:289-292

\begin{abstract}
Introduction
Laryngeal cancer with invasion of soft tissues of the neck including the skin is staged as T4a disease according to the TNM classification by the AJCC in 2010 . The traditional treatment for this locally advanced disease is through total laryngectomy and en-bloc removal of the involved cervical skin followed by reconstruction by one of the regional flaps. In this study, we present our experience with the use of two regional flaps, namely, the pectoralis major myocutaneous flap and the deltopectoral flap, for reconstruction of T4a laryngeal cancer infiltrating the cervical skin.
\end{abstract}

Patients and methods

A total of 11 patients were included in the study during the period from January 2013 to October 2016. Ours was a retrospective analytic study that included analysis of the preoperative, operative, postoperative, and follow-up patient data.

Results

Both flaps proved to be versatile for reconstruction of the locally advanced cancer larynx and provided a simple alternative for the more complex free flap surgery.

\author{
Keywords: \\ cancer larynx, deltopectoral flap, pectoralis major myocutaneous flap \\ Egypt J Otolaryngol 34:289-292 \\ (c) 2018 The Egyptian Journal of Otolaryngology \\ $1012-5574$
}

\section{Introduction}

The occurrence of skin invasion in advanced cancer larynx is considered to be rare, as the usual mode of spread mostly occurs directly through mucosal surface or submucosal infiltration [1]. Laryngeal cancer with invasion of soft tissues of the neck including the skin is staged as $\mathrm{T} 4 \mathrm{a}$ disease according to the TNM classification by the AJCC in 2010. The traditional treatment for this locally advanced disease is through total laryngectomy and enbloc removal of the involved cervical skin followed by reconstruction by one of the regional flaps [2-5].

In this study, we present our experience with the use of two regional flaps, namely, the PMMF and the DP flap, for reconstruction of $\mathrm{T} 4 \mathrm{a}$ laryngeal cancer infiltrating the cervical skin.

\section{Patients and methods}

This study was conducted at Otolaryngology-Head and Neck Surgery Department, Alexandria University Hospitals, Egypt. A total of 11 patients were included in the study during the period from January 2013 to October 2016. Our study was a retrospective analytic study that included analysis of the preoperative, operative, postoperative, and follow-up patient data.

\section{Preoperative details}

All patients were subjected to complete history taking, including age, sex, smoking, presenting symptoms, and previous interventions either surgical (tracheostomy or partial laryngectomy) or nonsurgical (radiotherapy or chemotherapy). Complete examination was done, including general examination (with emphasis on comorbidities that may affect the course of surgery such as chest condition and diabetic state) in addition to formal ENT examination. Radiologic examination included computed tomography of the larynx and plain chest radiography. Direct laryngoscopy and biopsy was done to assess the extension of the disease for proper staging. Informed consent was taken after detailed counseling of patients about the nature of their disease and the decided treatment plan. Routine preoperative investigations (complete blood count (CBC), liver function test (LFT), renal function test (RFT), coagulation profile, chest $x$-ray (CXR), and ECG) were done, and the fitness of all patients was assessed by the anesthesiologist.

\section{Operative details}

Total laryngectomy was done for all patients with excision of the involved cervical skin. All patients needed the thyroid gland to be completely removed with the specimen. Intraoperative frozen sections were

This is an open access journal, and articles are distributed under the terms of the Creative Commons Attribution-NonCommercial-ShareAlike 4.0 License, which allows others to remix, tweak, and build upon the work non-commercially, as long as appropriate credit is given and the new creations are licensed under the identical terms. 
obtained to ensure the adequacy of the surgical margins. Pharyngeal closure was done using Vicryl (Ethicon Inc., VA, USA) 3/0 stitches in three-layer fashion. The first layer was the interrupted extramucosal layer, and the second and the third layers were taken through the serosa and the preserved inferior constrictors, respectively.

The resultant skin defect was reconstructed immediately with either the PMMF or the DP flap. Our choice was dependent on whether previous radiotherapy to the neck was taken or not in addition to the BMI of the patients. According to the policy of our institute, all patients remained on NGT feeding for 14 days, after that time barium swallow was done with the nasogastric tube (NGT) in place. Details of the postoperative course were assessed including development of complications such as pharyngocutaneous fistula (PCF) or delayed wound healing, as well as the general postoperative complications. The duration of follow-up exceeded 3 years for all patients.

\section{Results}

Table 1 summarizes the results of the study.

A total of 11 patients (10 males and one female) were enrolled in the study. BMI was calculated for all

Table 1 Summary of the results of the study

\begin{tabular}{lc}
\hline Parameters & Results \\
\hline Age (range) (years) & $47-67$ \\
Sex & \\
$\quad$ Male & 10 \\
Female & 1 \\
BMI & \\
$\quad<25$ & 5 \\
$25-30$ & 2 \\
$>30$ & 4 \\
Primary tumor site & \\
Supraglottic & 7 \\
Glottic & 3 \\
Subglottic & 1 \\
Previous tracheostomy & 3 \\
Previous partial surgery & 2 \\
Previous RT & 2 \\
Reconstruction method & \\
PMMF & \\
DP flap & 6 \\
Postoperative RT & 5 \\
Postoperative complications & 11 \\
Fistula & \\
Wound healing problem & 2 \\
\hline
\end{tabular}

DP, deltopectoral; PMMF, pectoralis major myocutaneous flap; $\mathrm{RT}$, radiotherapy. patients. BMI was found less than 25 in five cases, between 25 and 30 in two cases, and above 30 in four cases. Three patients had tracheostomy done before the definitive surgery owing to airway compromise. Radiotherapy was received by two patients where salvage surgery deemed necessary. Regarding the reconstructive method utilized, PMMF was done in six cases (Fig. 1a and b) whereas DP flap was done in five cases (Figs 2-5).

All patients received radiotherapy in the postoperative period. PCF occurred in two cases, whereas wound healing problems were seen in two patients.

\section{Discussion}

Advanced cancer larynx extending to involve the skin of the anterior neck is a rare situation but represents a challenging situation to the surgeon as invasion of the soft tissues and the skin of the neck cannot be controlled by the routine surgery [6].

Our choice was dependent on the BMI of the patients. $\mathrm{BMI}$ was found to be less than 25 in five cases, between 25 and 30 in two cases, and above 30 in four cases. We preferred to use the DP flap in patients with BMI more than 25 as PMMF tended to be bulky in these cases. Calli et al. [7] addressed the effect of BMI on the selection of the flap for pharyngeal reconstructions. In their study, there was a tendency to use radial forearm free flap in overweight or obese patients.

The DP flap is a versatile flap that has proven to be useful for a variety of reconstructive problems, including simple resurfacing of the neck and reconstruction of oral and oropharyngeal defects. Bakamjian et al. [8] noted that the flap was strikingly resistant to necrosis and could often be used without delay. The attributed success of this procedure is based on both abundant arterial supply and good venous drainage afforded by the dependent final position of the pedicle of the flap. Although the DP flap is not an 'arterialized' flap throughout its entire length, it is rarely necessary to exceed a $2: 1$ length to width ratio by more than a small factor when using this flap for reconstruction.

The DP flap is based on the perforating branches of the internal mammary artery from the second through the fourth intercostal space. The distal portion of the flap, once the thoracoacromial branch is divided, is perfused only by the subdermal plexus from the pectoral portion. Venous drainage is afforded through the venae comitantes of the internal mammary artery [9]. 

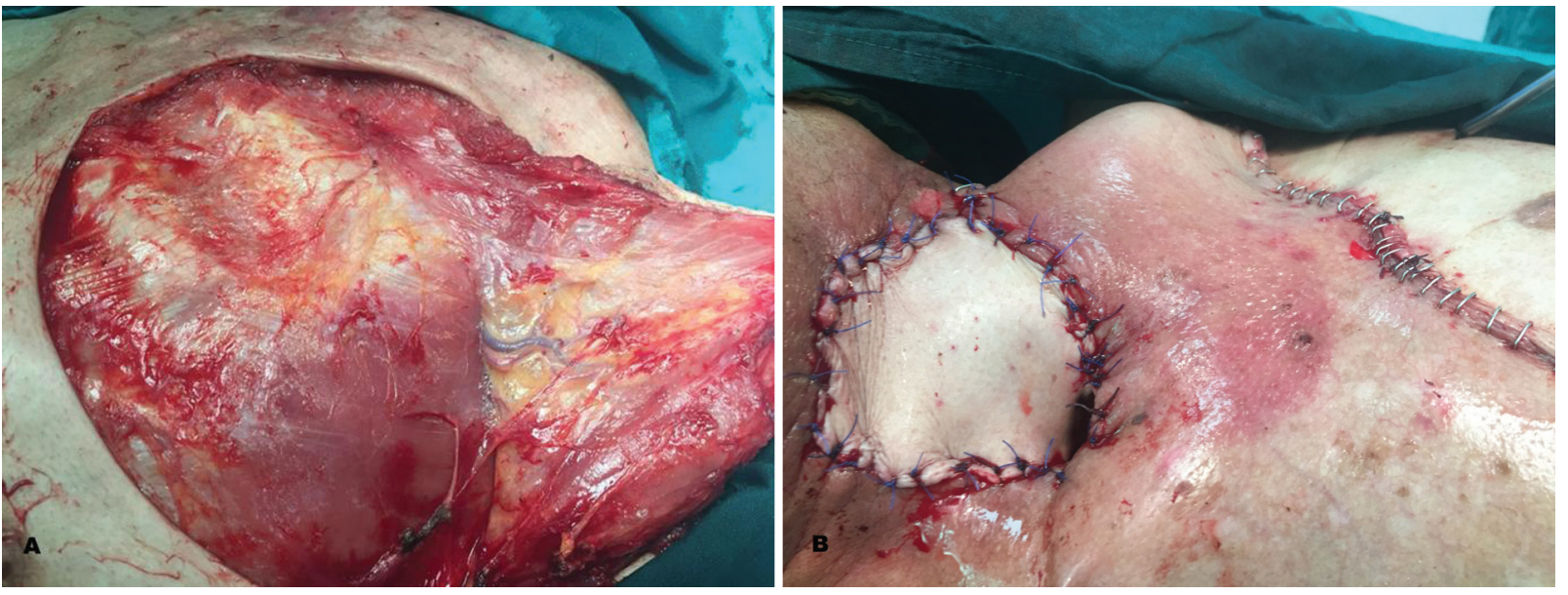

(a, b) Demonstration of harvesting and inset of the pectoralis major myocutaneous flap.

Figure 2

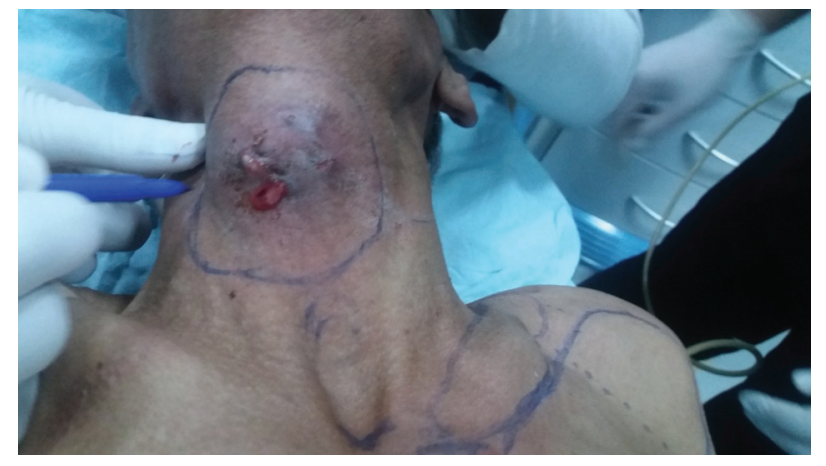

Preoperative appearance of cancer larynx with frank skin invasion.

In the current study, DP flap was used in five patients and PCF occurred only in one (20\%) case. This patient had received radiotherapy in the preoperative period. Other complications such as wound dehiscence occurred in another patient and were managed in a conservative manner.

One of the true recent advances in head and neck reconstruction has been the development and application of myocutaneous flaps. The limitations of reconstructive techniques with cutaneous flaps and the understanding of the circulation of the muscles and their overlying skin have ushered in a new era of one-stage reconstructions at a variety of sites [10]. Distinct advantages to using pedicled flaps are no need for microsurgical skills or equipment and the short time required to raise and inset these flaps compared with free tissue transfer [11].

The pectoralis major flap proved to be reliable and consistently useful. This flap has great length and can provide generous amounts of well-vascularized skin for reconstruction $[12,13]$. The PMMF was originated
Figure 3

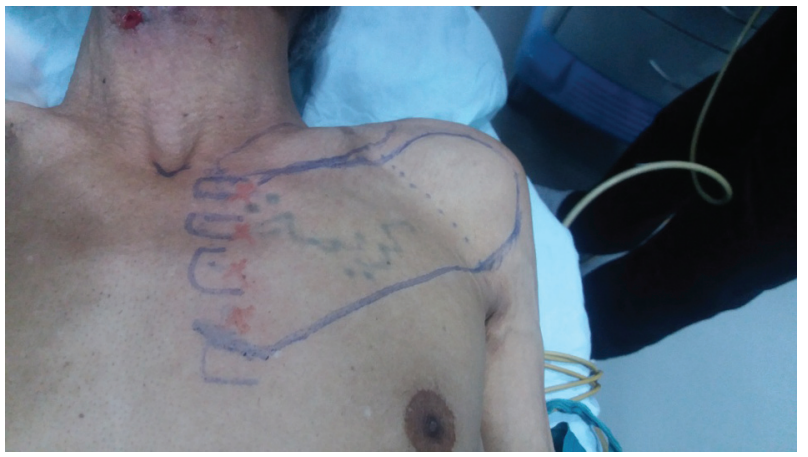

Marking of the deltopectoral flap.

and developed by Ariyan [14] for head and neck reconstruction after surgical resection of malignant tumors. The PMMF is an axial pattern flap, and its major feeding vascular pedicle is the pectoral branch of the thoracoacromial artery [15]. This vessel passes deep through the clavipectoral fascia medial to the insertion of the pectoralis minor muscle. From here, it is located on the deep surface of the pectoralis major muscle [16]. The vascular axis can be outlined by drawing a line connecting the shoulder prominence and the xiphoid process. The vessels can then be drawn on the chest as exiting at $90^{\circ}$ to the midportion of the clavicle until they reach this line, then coursing along the line. The pectoralis major may be transported in part or in whole on its feeding vessel $[17,18]$.

The thickness of the PMMF in addition to its constant blood supply makes it a suitable and reliable flap for reconstruction soft tissue defects [19,20]. Patel and Keni [21] reported that the use of PMMF in salvage laryngectomy following radiotherapy significantly reduced the incidence of PCF from 50 to $0 \%$. In our study, PMMF was used in six patients, of whom 


\section{Figure 4}

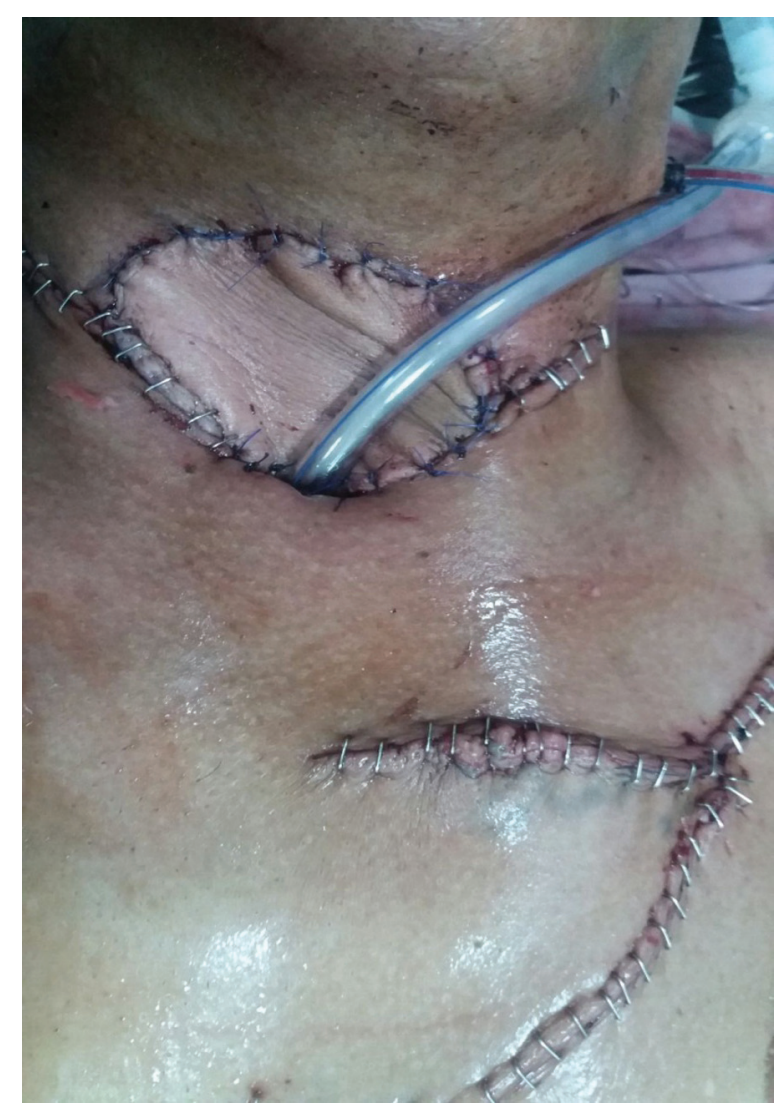

Immediate postoperative picture for the flap inset and donor site closure.

\section{Figure 5}

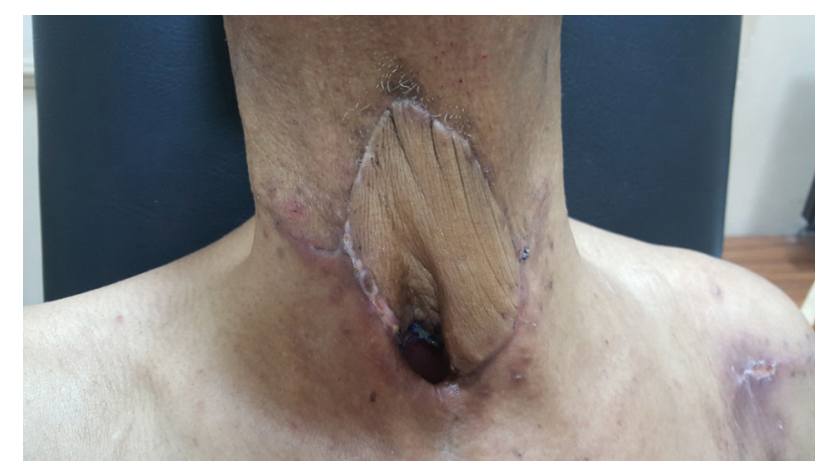

Two weeks postoperative.

one patient experienced PCF (16.67\%). The reported incidence of PCF following total laryngectomy ranges from 3 to $65 \%$ [22,23]. Wound problems occurred in one patient, representing an incidence of $16.67 \%$, which is still comparable with other studies [24].

\section{Financial support and sponsorship}

Nil.

\section{Conflicts of interest}

There are no conflicts of interest.

\section{References}

1 Rifai M, Mebed H, Bassiouni M. Direct extension of laryngeal carcinoma to the skin of the neck. J Laryngol Otol 1990; 104:824-826.

2 Jin J, Liao Z, Gao L, Huang X, Xu G. Analysis of prognostic factors for T1NOMO glottic cancer treated with definitive radiotherapy alone: experience of the cancer hospital of Peking Union Medical College and the Chinese Academy of Medical Sciences. Int J Radiat Oncol Biol Phys 2002; 54:471-478.

3 Haugen $\mathrm{H}$, Johansson KA, Mercke C. Hyperfractionated-accelerated or conventionally fractionated radiotherapy for early glottic cancer. Int J Radiat Oncol Biol Phys 2002; 52:109-119.

4 Back G, Sood S. The management of early laryngeal cancer: options for patients and therapists. Curr Opin Otolaryngol Head Neck Surg 2005; 13:85-91.

5 Spector GJ, Sessions DG, Lenox J, Newland D, Simpson J, Haughey BH. Management of stage IV glottic carcinoma: therapeutic outcomes. Laryngoscope 2004; 114:1438-1446.

6 Croce A, Moretti A, Bianchedi M, Neri G, Falcone G. Widened forwarding total laryngectomy (squared laryngectomy). Acta Otorhinolaryngol Ital 1995; 15:355-360.

7 Calli C, Teknos TN, Agrawal A, Schuller DE, Ozer E, Songu M. Does body mass index matter while selecting the flap type for pharyngeal reconstruction? J Craniofac Surg 2014; 25:780-782.

8 Bakamjian VY, Long M, Rigg B. Experience with the medially based deltopectoral flap in reconstructive surgery of the head and neck. $\mathrm{Br} J$ Plast Surg 1971; 24:174-183.

9 Greenstein B, Mora W, Strauch B. Reconstruction. In: Silver C, editor. Atlas of head and neck surgery. New York, NY: Bronx; 1986. pp. 47-73.

10 Ariyan S. Myocutanous flaps. In: Silver C, editor. Atlas of head and neck surgery. New York, NY: Churchill Livingstone; 1986. pp. 50-60.

11 Hurvitz KA, Kobayashi M, Evans GR. Current options in head and neck reconstruction. Plast Reconst Surg 2006; 118:122-133.

12 Milenovic A, Virag M, Uglesic V, Aljinovic-Ratkovic N. The pectoralis major flap in head and neck reconstruction: first 500 patients. J Craniomaxillofac Surg 2006; 34:340-343.

13 Cordova A, Corradino B, Pirrello R, Di Lorenzo S, Dispenza C, Moschella F. Surgical treatment of pharyngostomes in irradiated patients. Our experience with musculocutaneous pectoralis major flap and hyperbaric oxygen therapy. Acta Otolaryngol 2005; 125:759-764.

14 Ariyan S. Further experiences with the pectoralis major myocutaneous flap for the immediate repair of defects from excisions of head and neck cancers. Plast Reconst Surg 1979; 64:605-612.

15 Rikimaru H, Kiyokawa K, Inoue Y, Tai Y. Three-dimensional anatomical vascular distribution in the pectoralis major myocutaneous flap. Plast Reconstr Surg 2005; 115:1342-1352.

16 Spriano G, Piantanida R, Pellini R. Hypopharyngeal reconstruction using pectoralis major myocutaneous flap and pre-vertebral fascia. Laryngoscope 2001; 111:544-547.

17 Baek SM, Biller HF, Krespi YP, Lawson W. The pectoralis major myocutaneous island flap for reconstruction of the head and neck. Head Neck Surg 1979; 1:293-300.

18 Withers EH, Franklin JD, Madden JJ Jr, Lynch JB. Pectoralis major musculocutaneous flap: a new flap in head and neck reconstruction. Am J Surg 1979; 138:537-543.

19 Ariyan S, Cuono CB. Use of the pectoralis major myocutaneous flap for reconstruction of large cervical, facial or cranial defects. Am J Surg 1980; 140:503-506.

20 Leemans CR, Balm AJM, Gregor RT, Hilgers FJM. Management of carotid artery exposure with pectoralis major myofascial flap transfer and splitthickness skin coverage. J Laryngol Otol 1995; 109:1176-1180.

21 Patel UA, Keni SP. Pectoralis myofascial flap during salvage laryngectomy prevents pharyngocutaneous fistula. Otolaryngol Head Neck Surg 2009; 141:190-195.

22 Bresson K, Rasmussen H, Attrup Rasmussen P. Pharyngocutaneous fistulae in totally laryngectomized patients. J Laryngol Otol 1974; 88:835-842.

23 Thawley SE. Complications of combined radiation therapy and surgery for carcinoma of the larynx and inferior hypopharynx. Laryngoscope 1981; 91:677-700.

24 Grau C, Johansen LV, Hansen HS, Andersen E, Godballe C, Andersen LJ, et al. Salvage laryngectomy and pharyngocutaneous fistulae after primary radiotherapy for head and neck cancer: a national survey from Dahanca. Head Neck 2003; 25:711-716. 